\title{
Thermographic Assessment of the HAZ Properties and Structure of Thermomechanically Treated Steel
}

\author{
Jacek Górka ${ }^{1}$ • Damian Janicki ${ }^{1}$ - Marek Fidali ${ }^{2}$ • \\ Wojciech Jamrozik ${ }^{2}$
}

Received: 2 November 2016 / Accepted: 23 October 2017 / Published online: 1 November 2017 (C) The Author(s) 2017. This article is an open access publication

\begin{abstract}
Thermomechanically processed steels are materials of great mechanical properties connected with more than good weldability. This mixture makes them interesting for different types of industrial applications. When creating welded joints, a specified amount of heat is introduced into the welding area and a so called heataffected zone (HAZ) is formed. The key issue is to reduce the width of the HAZ, because properties of the material in the HAZ are worse than in the base material. In the paper, thermographic measurements of HAZ temperatures were presented as a potential tool for quality assuring the welding process in terms of monitoring and control. The main issue solved was the precise temperature measurement in terms of varying emissivity during a welding thermal cycle. A model of emissivity changes was elaborated and successfully applied. Additionally, material in the HAZ was tested to reveal its properties and connect changes of those properties with heating parameters. The obtained results prove that correctly modeled emissivity allows measurement of temperature, which is a valuable tool for welding process monitoring.
\end{abstract}

Keywords Emissivity correction · HAZ (Heat-affected zone) · Thermography · Thermomechanically treated steels $\cdot$ Welding

Selected papers from Third Conference on Photoacoustic and Photothermal Theory and Applications.

$凶$ Wojciech Jamrozik

wojciech.jamrozik@polsl.pl

1 Welding Department, Silesian University of Technology, Konarskiego 18a str, 44-100 Gliwice, Poland

2 Institute of Fundamentals of Machinery Design, Silesian University of Technology, Konarskiego 18a str, 44-100 Gliwice, Poland 


\section{Introduction}

Elaboration of new materials is a task that is demanded by constantly developing industries. The properties of these materials are strictly specified, and the whole production and treatment process has to be entirely controlled to assure that certain structural material has proper microstructure, strength, weight, etc. HSLA (high-strength low-alloy) steels having ferritic, ferritic/pearlitic, ferritic/bainitic, bainitic, or tempered martensite microstructures allow a large reduction in weight of the elements and structures produced from them. One of the most interesting and widely applied groups of materials are thermomechanically processed steels. Reducing the thickness of metal sheets produced in the process of thermomechanical rolling (thermomechanical controlled processing-TMCP) for the automotive industry, shipbuilding, oil industry, and many branches of civil engineering led to a reduction in the cost with simultaneous preservation of all mechanical properties of material.

This type of steel is characterized by high strength combined with high toughness, high resistance against cold cracks, great formability, and low carbon content or equivalent (CE). The last two aforementioned features are especially useful when elements made of this steel have to be joined with some welding technique. This is due to the fact that low CE is most important for good weldability. Moreover, TMPC steels are characterized by high toughness in the heat-affected zone (HAZ). All of these factors result in high reliability of TMPC steels, that can be applied in welded structures. The use of this type of steel reduces the cost of welding by reducing the cross section of the joints, which leads to reduced consumption of additional materials, shortened welding time, and a reduction in expenditures on testing joints [1-4].

There is a strong interest in applications of TMPC steels for the construction of various structures, including those operating in extreme climatic conditions requiring constant improvements in production technology and joining of these steels through research and control of materials and process parameters. One possible way of controlling the welding process can be by monitoring and evaluating the HAZ, which has a crucial influence on the properties of joint and further constructional and functional properties of welded assemblies. To get the correct microstructure in the HAZ, it is necessary to control the amount of energy that is delivered into the welding area. In other words, it is demanded that the temperature of the process has to be precisely controlled to avoid unwanted changes of microstructure that can cause irreversible changes in the properties of material in the HAZ (weakening in comparison with the base material).

In the paper, the concept of welding process monitoring and the results of the study's influence on the thermal cycle generated during welding on the properties of the microstructure of materials are presented. The obtained results have proven that the proposed method has the potential to be applied in manufacturing processes to achieve optimal functional properties of welded joints.

\section{Welding of Thermomechanically Treated Steel}

Welding of TMPC steels requires assurance of the appropriate conditions and parameters, as the welding process can be performed using various technologies. Welding 
properties of TMPC steels are mainly determined by their weldability, which depends on the used material's properties, proposed technology and additional material's properties. Weldability cannot be expressed by a single value; however, it can be determined on the basis of appropriate studies. It is widely known from literature that optimal welding properties of TMPC steels in terms of hardness, impact strength, and tensile strength should be achieved. Moreover, welding parameters should consider environmental conditions that have an additional influence on welding joint properties. According to that, physical, chemical, and mechanical properties of a joint and the HAZ are determined by a combination of welding parameters and conditions.

Since the HAZ's properties are mainly responsible for the strength of welded joints, it is important to precisely know what type of phase transition occurs in this zone for certain material and process parameters. The nature of the HAZ's formation is largely determined by the welding thermal cycle. The welding thermal cycle is described by changes of temperatures at certain points in the joint as a function of time. It covers changes of temperatures caused by heat transfer at each point of joint volume and the effects of those changes. The type of thermal cycle that a welded material has undergone, especially in the HAZ, affects the structural and mechanical properties of the joint. In other words, properties of the HAZ are determined by the maximum temperature of the thermal cycle and cooling time $t_{8 / 5}$ (in the range $800^{\circ} \mathrm{C}-500^{\circ} \mathrm{C}$, Fig. 1). Knowledge of the thermal cycles in the HAZ at individual points allows assess to microstructure in the neighborhood area of those points, and as a broader concept, it can be the basis for elaboration of CCT (continuous cooling transformation) diagrams. CCT diagrams are mainly used for: prediction of the structural composition of HAZ, a preliminary assessment of the tendency to hardening of the HAZ of the welded joint and thus the tendency of the steel for cold cracking in the welding process, determination of welding conditions (arc linear energy and preheat temperature) required to obtain joints without cold cracks and with good plastic properties, securing the area against brittle cracking.

The thermal cycle can be simple (Fig. 1) or complex (Fig. 2). The cycle is simple when single-layer welding is performed, and each point of the HAZ is only one heated by the heat source. A complex thermal cycle occurs at a given HAZ point when multilayer welding is made. In this case, each HAZ point can be heated and cooled several times according to the number of seams made. Among the methods of determining transformation temperatures in a welding thermal cycle, conditions of several groups can be distinguished: direct methods, e.g., in situ, where transformation temperatures are assessed during welding, or indirect methods, where thermal conditions that will appear during welding are simulated as precisely as possible [5-7]. During this research, the second approach was applied.

When welding TMPC steel, niobium, titanium, and vanadium are introduced to the joint area. They are released when the joint cools down, and they take the form of carbides and carbonitrides. The amount of dispersions depends on the cooling rate. Faster cooling means that the amount of dispersions in solution will increase. This is similar to the HAZ, where an increase in diffusionless and bainite transition products is noticeable. Those types of structures are responsible for a decrease in impact strength, particularly in the case of a wide HAZ. This effect is compounded when welding is made with high linear energy and the cooling time $t_{8 / 5}$ increases. 


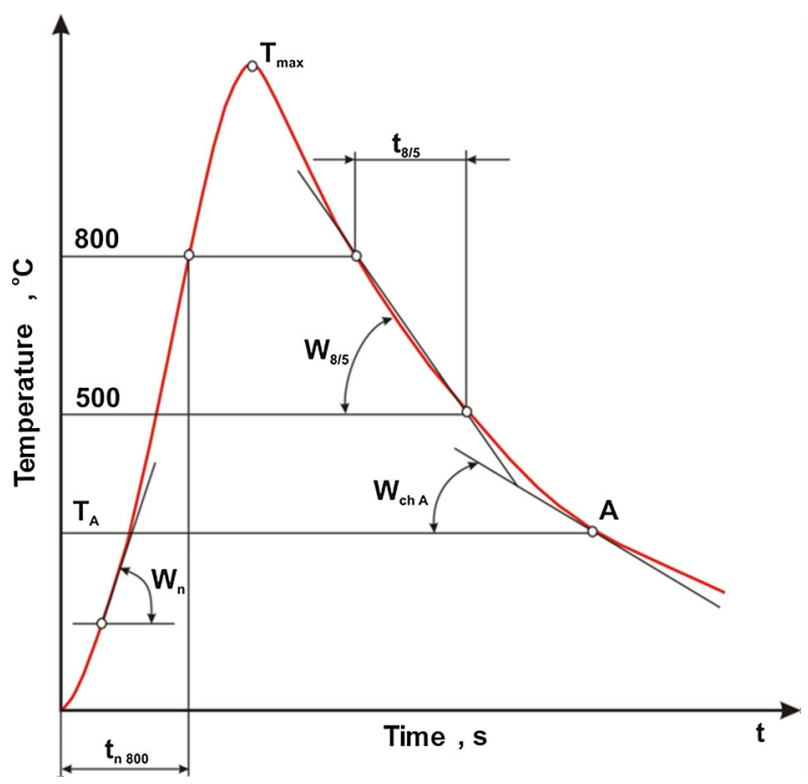

Fig. 1 Simple thermal cycle with marked characteristic parameters essential for joint quality; $\mathrm{W}_{\mathrm{chA}}-$ instantaneous cooling speed for point $\mathrm{A}, \mathrm{W}_{8 / 5}$ - average cooling speed form $800{ }^{\circ} \mathrm{C}$ to $500{ }^{\circ} \mathrm{C}, \mathrm{t}_{8} / 5^{-}$time needed to cool form $800{ }^{\circ} \mathrm{C}$ to $500^{\circ} \mathrm{C}$ [5]

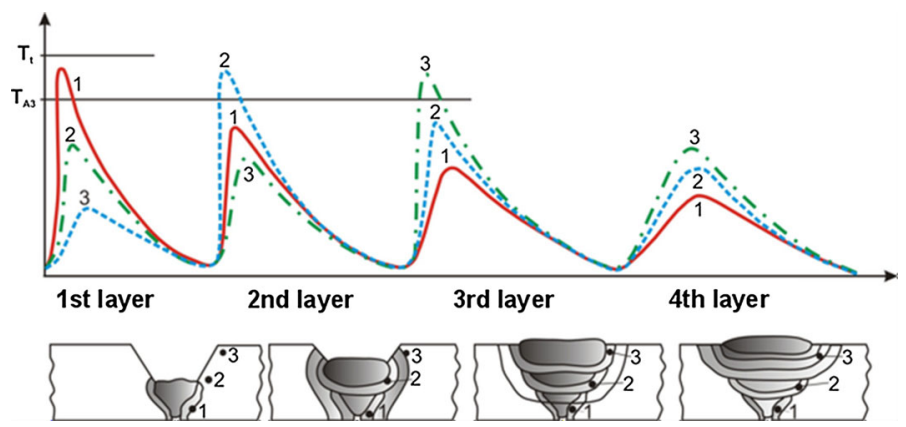

Fig. 2 Exemplary complex welding thermal cycle; 1, 2, 3-points of temperature measurement, $\mathrm{T}_{\mathrm{t}}$ temperature of steel melting, $\mathrm{T}_{\mathrm{A} 3}$ - temperature of austenitic transformation [5]

In the case of a high cooling rate of typical microstructure, TMPC steel's HAZ has a lower amount of bainite, which is characterized by satisfactory resistance to brittle fracture. When the amount of heat introduced to the joint is high and the material in the HAZ is held at a high temperature for a longer period of time, the cooling rate is relatively low. This leads to a growth of austenite grains, and especially in the zone adjacent to the weld line, formation of structures having elastic properties. In the structure of the HAZ upper bainite, grain boundary ferrite and ferrite side plates dominate. The formation of a austenitic-martensitic phase is enhanced by withstanding a superheated part of the HAZ in the temperature range of Ac1-Ac3 during multiple layer welding. Softening of the HAZ in welded joints, especially in thermomechan- 
ically treated steels with accelerated cooling, does not influence immediate strength. Nevertheless, it may increase the tendency to brittle fracture and fatigue [8].

According to the aforementioned changes in microstructure, phase mixture, and material properties, there is a strong relationship between temperature introduced into the material during production or joining process and properties of this material. In real life applications, properties of the HAZ are different from those of the base material, but these changes, as well as depth (width) of the HAZ, can be minimized by monitoring and control of the welding process.

\section{Monitoring of HAZ Properties}

During the welding process, different instabilities can occur. Some instabilities follow from faults of welding equipment, some from errors in the preparation of welded parts, and others from incorrectly set welding parameters. In the case of arc welding, instabilities of the welding speed, welding current, and electric arc voltage lead to changes in the linear energy introduced into the joint, and as a consequence, this influences the HAZ's properties. Monitoring of the HAZ during or directly after welding can indicate weak points of the welded joint and avoid further problems with operation of weldment. The HAZ could be monitored in different ways. The simplest one is visual inspection where, on the basis of color and shape of oxide boundaries, it is possible to evaluate the HAZ's properties and indicate areas of the joint where instability occurred (Fig. 3). Such method is rather approximate and not precise.

A more accurate approach to observing and controlling HAZ properties could be the application of infrared thermography [9-11]. An infrared camera has the ability to observe a whole scene during welded joint creation and represent it in the form of an infrared image (thermogram) where each pixel corresponds to a temperature value measured on the surface. Taking into account pixel lines across the joint and the $\mathrm{HAZ}$ area, it is possible to create a temperature profile which precisely describes the temperature distribution at a certain moment of welding (Fig. 4).

Tracking and observation of the profile can be the basis of a monitoring and control system which can give information about changes in the temperature in the HAZ caused by welding instabilities. On the basis of the profile series, it is possible to identify functions time-temperature $\mathrm{T}(\mathrm{t})$ showing the cooling process in the HAZ

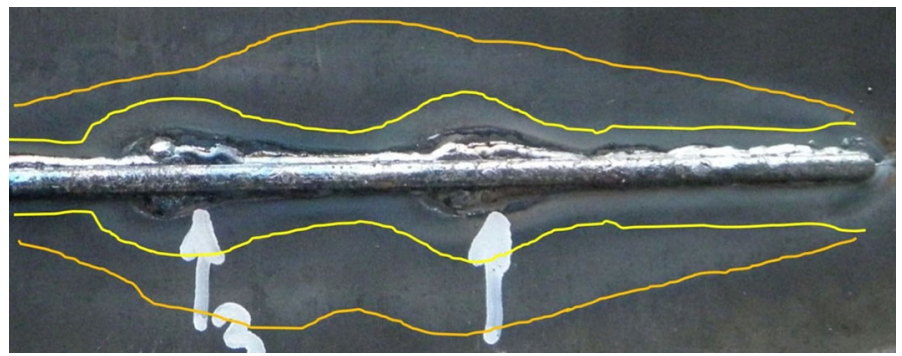

Fig. 3 Simple visual method of identification of HAZ properties 
(a)

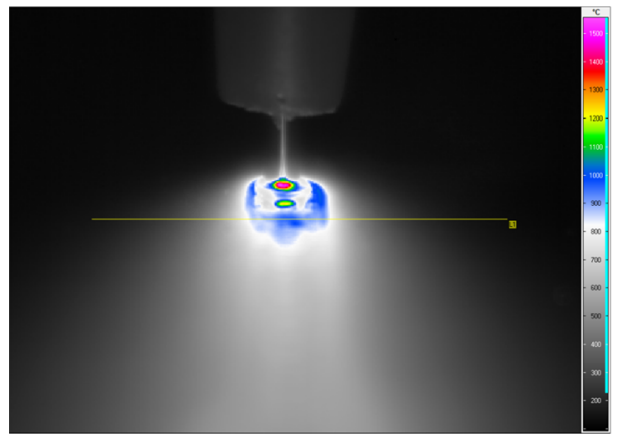

(b)

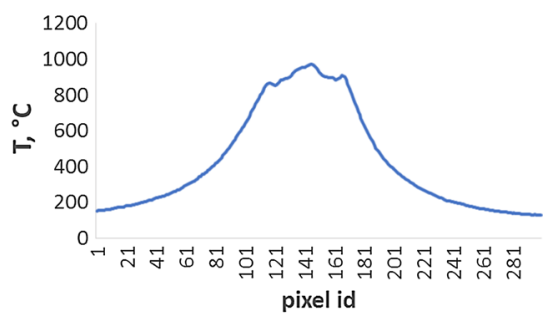

Fig. 4 Exemplary infrared image acquired during arc welding and temperature profile across the joint and HAZ

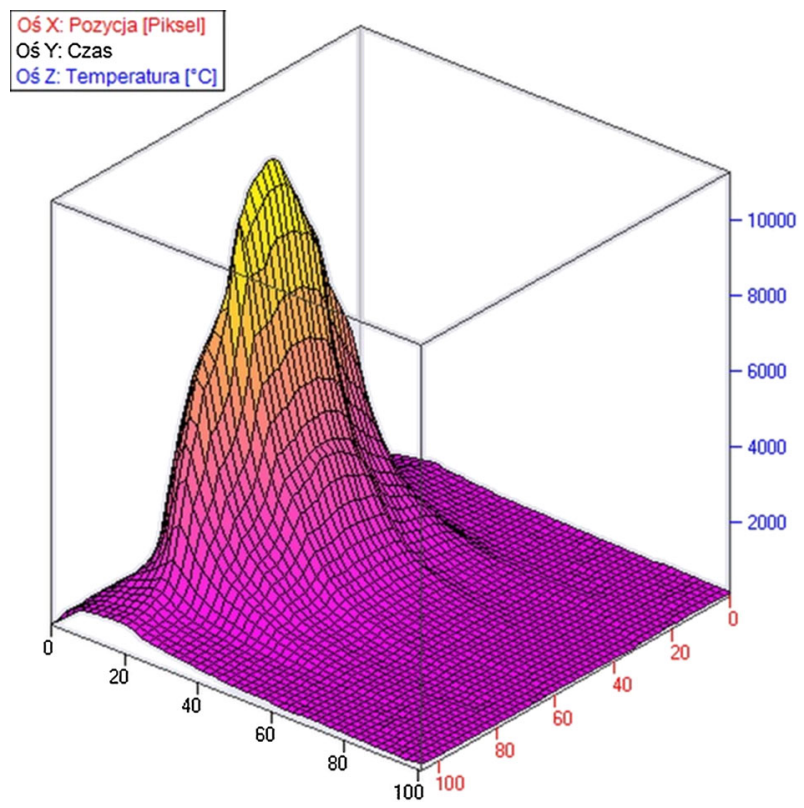

Fig. 5 Exemplary series of temperature profiles for a single cross section of a welded joint

(Fig. 5). Using this function, one can estimate, e.g., $\mathrm{t}_{8 / 5}$ as a parameter describing the HAZ's properties. The $t_{8 / 5}$ time could be treated as a diagnostic parameter and used to assess welding process stability.

In this approach, one problem should be considered, namely that the temperature measurements of metallic surfaces that use infrared thermography are not easy because of the material's emissivity [12]. Emissivity of metals is generally very low at room temperature, but increases with increase of a metallic object's temperature. Thus, during the welding process, emissivity of welded parts is transient, which makes these kinds of temperature measurements performed by infrared camera not valid. This 
problem can be overcome by using a model of emissivity changes over the temperature changes of the welded parts. More specifically, the model should be especially accurate for temperatures ranging between $500-800^{\circ} \mathrm{C}$, which is necessary to obtain cooling time $t_{8 / 5}$. In order to estimate the influence of errors of temperature reading caused by emissivity on estimation of $t_{8 / 5}$ time, as well as to verify whether it is possible to build a correction model of measured temperatures, experimental research was conducted.

\section{Experimental Research Work}

Experimental research was carried out in the Laboratory of Welding Technologies (Welding Department, Silesian University of Technology) using a specially constructed bench equipped with a resistive heating source dedicated to simulation of a thermal cycle using an indirect method (Fig. 6). Investigated specimens were of dimensions $10 \times 10 \times 100 \mathrm{~mm}$ and were made of TMPC steel S700MC of chemical composition and mechanical properties presented in the Table 1.

In order to measure the temperature of the HAZ during the thermal cycle, an infrared camera and thermocouple measurement set were used. The measurement setup was connected to the computer which allowed control of the data acquisition task and storage of the data. A thermocouple was used for reference measurements. An isolated thermocouple type $\mathrm{K}(\mathrm{NiCr}-\mathrm{NiAl})$, whose measurement ranges from $-100^{\circ} \mathrm{C}$ to $1100^{\circ} \mathrm{C}$, was used. The thermocouple operated with the programmable temperature transmitter connected to ADC converter linked with the computer. The way the temperature sensor was coupled with the specimen is presented in Fig. 7.

Infrared images of the tested specimens were gathered using an uncooled infrared Infratec HR Head camera connected to the PC with installed acquisition and control software. The IR camera had a resolution of $640 \times 480 \mathrm{px}$ and was able to acquire images with a frame rate of $50 \mathrm{fps}$.

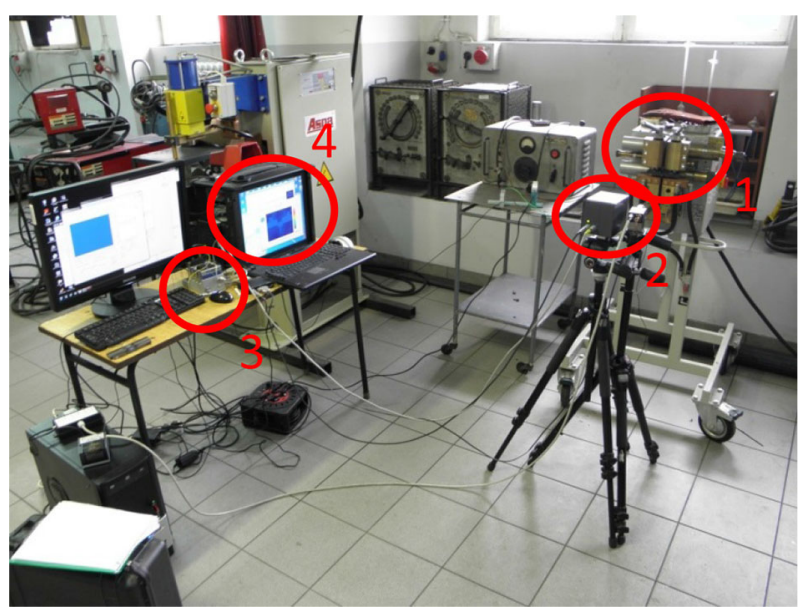

Fig. 6 Laboratory test bench. 1-heating source, 2-infrared camera, 3-thermocouple transmitter and ADC converter, 4-PC 


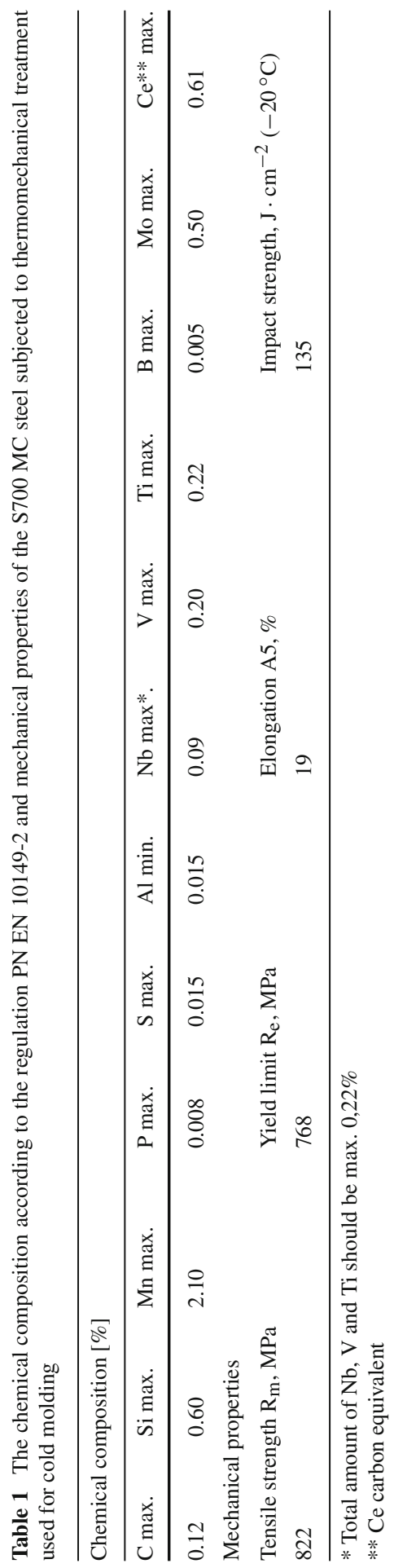



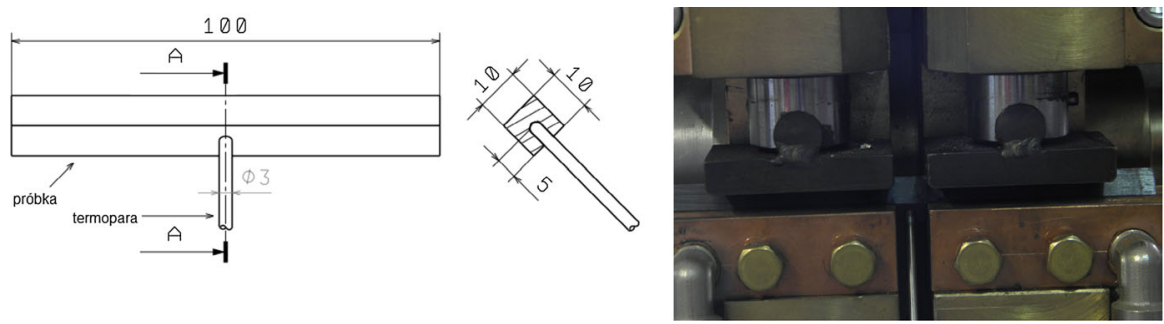

Fig. 7 Thermocouple mounting in the specimen

(a)

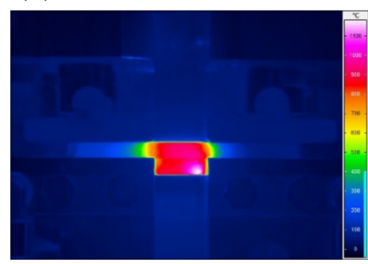

(b)

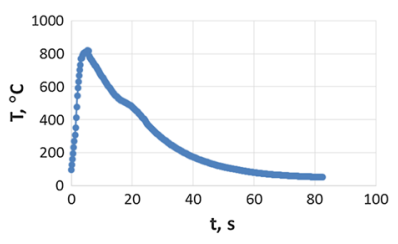

(c)

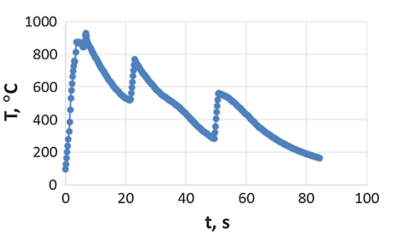

Fig. 8 Exemplary infrared image of the heating specimen (a) and temperature plot of the simple (b) and complex thermal cycle

The sample distance from the camera lens was $460 \mathrm{~mm}$, and the video ran at a height of $1550 \mathrm{~mm}$. The air temperature during the test was $23.7^{\circ} \mathrm{C}$. A series of simple thermal cycles for maximum temperatures ranging from $400^{\circ} \mathrm{C}$ to $1300^{\circ} \mathrm{C}$ were simulated. In the case of complex thermal cycles, it was decided to perform simulation for maximum temperatures from $1100{ }^{\circ} \mathrm{C}$ to $1300{ }^{\circ} \mathrm{C}$. The preheating time varies from $2.3 \mathrm{~s}$ to 5.6 $\mathrm{s}$. The test for each cycle temperature was repeated three times. Exemplary infrared image and plots of the temperature measured during the single and complex simulated thermal cycle are presented in Fig. 8.

\section{Results of the Research}

Monitoring of the HAZ's properties using an infrared camera required proper assessment of the temperature values. Because of the emissivity variation during the thermal cycle, it was necessary to find a way of temperature correction for the proper assessment of one of the HAZ's properties, namely maximum heating temperature and cooling time $t_{8 / 5}$.

Figure 9a presents temperature measurements during simple thermal cycles performed with use of the thermocouple and IR camera. In the case of the infrared camera, it was mean temperature value calculated over the measurement area presented in Fig. 9b. The temperature differences, in heating and cooling phases, are clearly visible and are presented in Fig. 10. Especially interesting are temperature differences in the phase of cooling where the temperature drops from $800{ }^{\circ} \mathrm{C}$ to $500{ }^{\circ} \mathrm{C}$. Relative errors of temperature readings from the IR camera referred to thermocouple values are $6.7 \%$ and $10.2 \%$, respectively, for $800^{\circ} \mathrm{C}$ and $500^{\circ} \mathrm{C}$. For temperatures 
(a)

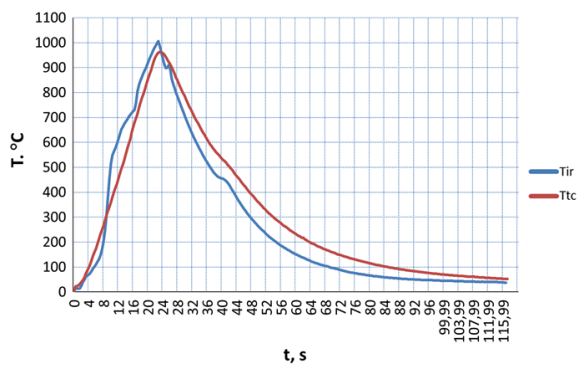

(b)

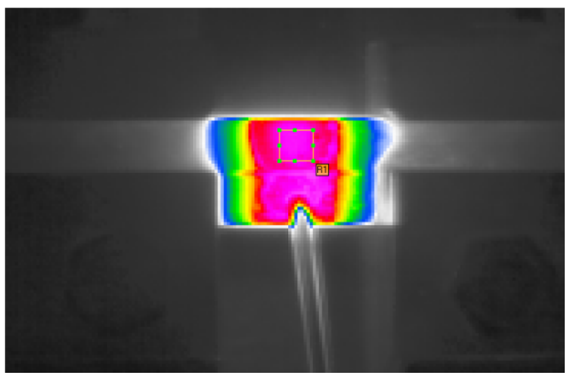

Fig. 9 Comparison of temperatures measured by thermocouple and IR camera (a) in rectangular measurement field definition (b)

Fig. 10 Absolute difference with thermocouple Tp and IR camera Tc between temperatures measured

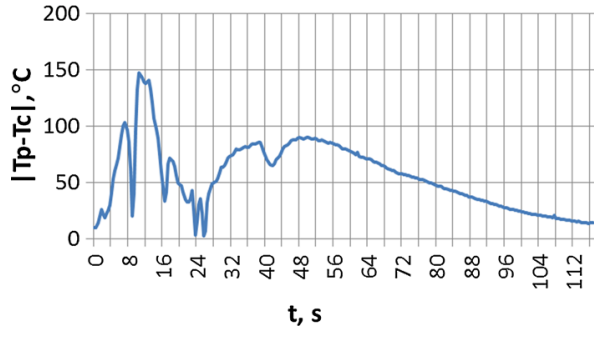
parameter assessment for thermocouple and IR camera measurements
Time at $800, \mathrm{t}_{8}, \mathrm{~s}$ Time at $500, \mathrm{t}_{5}, \mathrm{~s}$ Time $\mathrm{t}_{8} / 5, \mathrm{~s}$

\begin{tabular}{lccc}
\hline & Time at $800, \mathrm{t}_{8}, \mathrm{~s}$ & Time at $500, \mathrm{t}_{5}, \mathrm{~s}$ & Time $\mathrm{t}_{8} / 5, \mathrm{~s}$ \\
\hline Thermocouple & 28.8 & 41.6 & 12.8 \\
IR camera & 27.8 & 36.8 & 9.2 \\
Relative error, \% & 4.2 & 11.5 & 28.1 \\
\hline
\end{tabular}

$800^{\circ} \mathrm{C}$ and $500^{\circ} \mathrm{C}$ read from both the thermocouple and the IR camera, there were identified time values and the time $\mathrm{t}_{8 / 5}$ was calculated. Those times and errors are gathered in Table 2. It can be seen that errors for time parameters are similar to errors of temperatures; however, error for the evaluated time $t_{8 / 5}$ exceeds $28 \%$, which could have had an influence on the proper assessment of the HAZ's properties.

\subsection{Model of Temperature Correction}

Taking into consideration the differences in the time parameter $t_{8 / 5}$ calculated for temperatures measured using the thermocouple and the IR camera, it was decided to correct temperature measurements made by the IR camera using an elaborate correction model. The basis for the model identification was the ratio between the temperature measured by the IR camera and the temperature measured by the thermocouple:

$$
r_{i c}(t)=\frac{T_{i r p}(t)}{T_{t c p}(t)},
$$




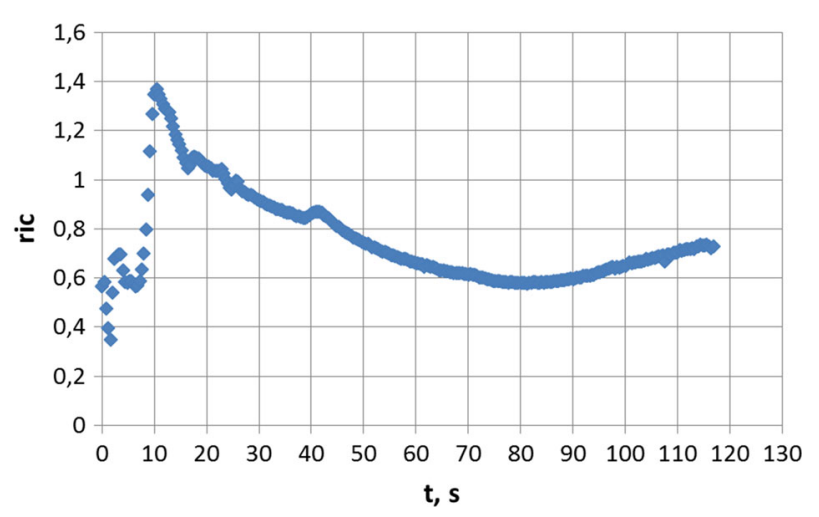

Fig. 11 Plot of temperatures ratio calculated using Eq. 1

where:

$\mathrm{T}_{\text {irp }}(\mathrm{t})$ - temperature measured with use of IR camera during preliminary research, $\mathrm{T}_{\mathrm{tcp}}(\mathrm{t})$ - temperature measured with the use of the thermocouple.

A plot of the temperature ratio for a simple thermal cycle is presented in Fig. 11. Temperature ratios can be considered functions of temperature measured by the IR camera $r_{i c}\left(T_{i r p}\right)$ (Fig. 12). This function can be suitable for identification of a model which can be further used for the calculation of corrected temperatures taken by the IR camera using temperatures read directly from the thermograms recorded at a constant emissivity during the whole thermal cycle. Corrected temperatures could be calculated in the following way:

$$
T_{\text {corr }}(t)=\frac{T_{i r}(t)}{r_{i c m}\left(T_{i r}\right)},
$$

where:

$\mathrm{T}_{\mathrm{ir}}(\mathrm{t})$ - temperature measured with use of IR camera during thermal cycle,

$\mathrm{r}_{\mathrm{icm}}\left(\mathrm{T}_{\mathrm{ir}}\right)$-ratio of temperatures calculated on the basis of the model identified during preliminary research.

In Fig. 12a, a plot of the function $\mathrm{r}_{\mathrm{ic}}\left(\mathrm{T}_{\mathrm{irp}}\right)$ was created during preliminary research. Using this function, we can simply identify, e.g., a second order polynomial model for the whole stage of the HAZ's cooling. However, the most interesting part of the cooling stage is when the temperature drops from $800^{\circ} \mathrm{C}$ to $500^{\circ} \mathrm{C}$ (Fig. $12 \mathrm{~b}$ ). A detailed analysis of this temperature range (Fig. 12b) reveals that the function can be modeled using a simple linear function (Eq. 3) where parameters $a$ and $b$ can be the result of a curve fitting using the data gathered during preliminary research:

$$
r_{i c m}=a T_{i r}+b
$$

On the basis of the data gathered during the research model, parameters were estimated and applied to correct the temperatures measured by the IR camera. A comparison of the temperatures before and after correction is presented in Fig. 13. 
(a)

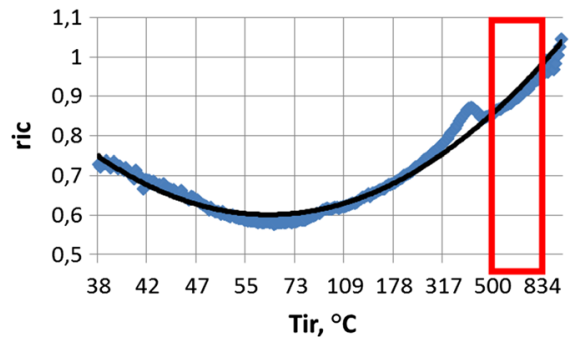

(b)

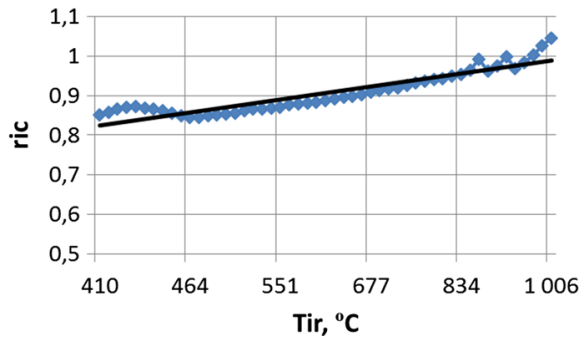

Fig. $12 \mathrm{r}_{\mathrm{ic}}\left(\mathrm{T}_{\mathrm{irp}}\right)$ function and possible models for (a) whole cooling stage, (b) part of cooling stage including temperature change from 800 to $500^{\circ} \mathrm{C}$

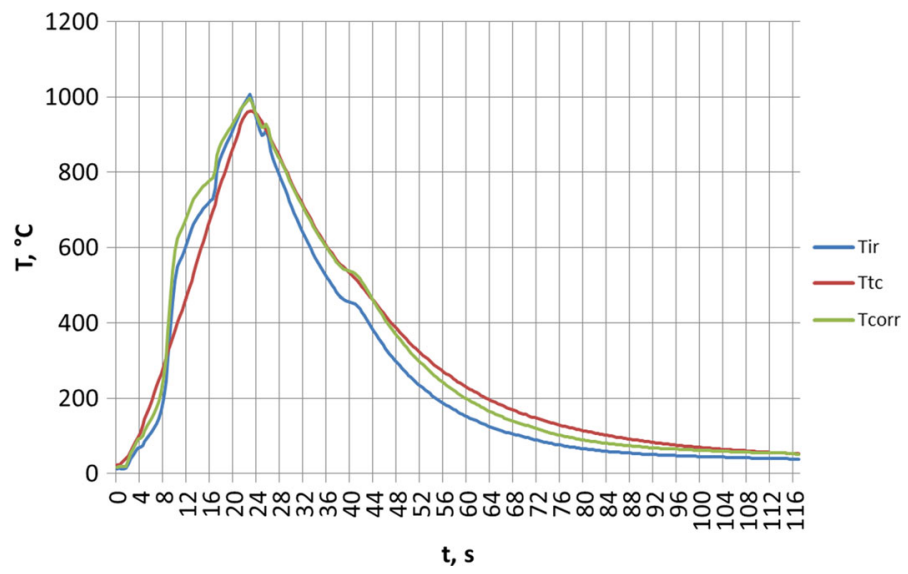

Fig. 13 Comparison of temperatures before and after correction using linear model

One can see that the curves of temperatures measured by the IR camera and corrected temperatures overlap in the range between $800^{\circ} \mathrm{C}$ and $500^{\circ} \mathrm{C}$. Calculated errors for temperatures $800{ }^{\circ} \mathrm{C}$ and $500^{\circ} \mathrm{C}$ were, respectively, $0.4 \%$ and $0.7 \%$, and time errors were the following: $\mathrm{t}_{8}-0 \%, \mathrm{t}_{5}-1.9 \%$, and $\mathrm{t}_{8 / 5}-6.2 \%$. It could be assumed that the application of such a model to real data recorded in similar conditions for similar specimens made of the same material improves the accuracy of the $t_{8 / 5}$ parameter's estimation.

\subsection{Estimation of Time $t_{8 / 5}$}

Taking into account the previous discussion, a model for temperatures acquired from the IR camera was identified and applied. Results of the evaluation of temperature parameters based on infrared images for simple and complex thermal cycles were presented in Table 3. As can be expected, time parameters increased with maximum temperature of the thermal cycle. Especially interesting is time $t_{8 / 5}$ which grows in a nonlinear manner, which shown in Fig. 14. As one can see, application of a complex thermal cycle significantly increases cooling time $t_{8 / 5}$ in comparison with a simple 
Table 3 Results in characteristic points of thermal cycle

\begin{tabular}{llccc}
\hline Cycle ID & Set temperature, $\left({ }^{\circ} \mathrm{C}\right)$ & $\mathrm{t}_{8},(\mathrm{~s})$ & $\mathrm{t}_{5},(\mathrm{~s})$ & $\mathrm{t}_{8 / 5},(\mathrm{~s})$ \\
\hline Simple cycle & & & & \\
5 & 800 & 8.0 & 21.4 & 13.4 \\
6 & 900 & 10.2 & 25.0 & 14.8 \\
7 & 1000 & 14.5 & 30.2 & 15.7 \\
8 & 1100 & 16.9 & 33.2 & 16.3 \\
9 & 1200 & 20.1 & 36.9 & 16.8 \\
10 & 1300 & 22.5 & 40.1 & 17.3 \\
Complex cycle & & & & \\
11 & $\mathrm{C} 1300(800) / 1100(500) / 900$ & 36.0 & 68.2 & 32.2 \\
12 & $\mathrm{C} 1100(500) / 900(400) / 700$ & 12.1 & 59.4 & 47.3 \\
13 & $\mathrm{C} 1000(500) / 700(300) / 500$ & 11.8 & 58.6 & 46.8 \\
\hline
\end{tabular}

Fig. 14 Trend of $t_{8 / 5}$ time values obtained during research

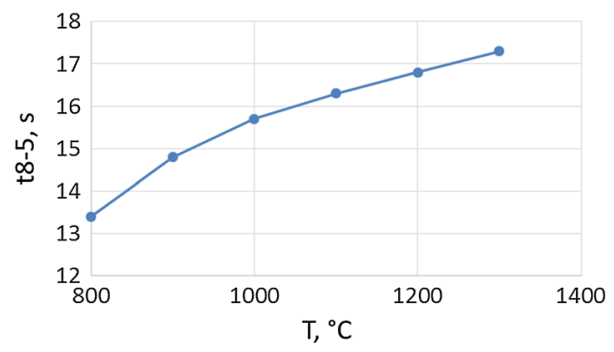

cycle which can have a negative influence on the microstructure of the welded joint and the HAZ's properties. Due to a small number of experiments performed for complex thermal cycles, it is not possible to unambiguously show the tendency of change of the time $\mathrm{t}_{8 / 5}$.

\subsection{Generalization of Corrected Model}

The proposed correction model is only valid for the investigated grade of steel 700 . However, there are many grades of steel and different conditions of welding that could exist. In such a situation, the accuracy of the parameter time $t_{8 / 5}$ could not be assured. The most crucial parameter influencing estimation of the temperature using the infrared camera is emissivity. As shown in [15], emissivity of the steel after surface treatment for low temperatures is low and increases with temperature due to surface oxidation. During this research, it was estimated that the emissivity of the specimens was about 0.9 at $800^{\circ} \mathrm{C}$ and 0.78 at $500{ }^{\circ} \mathrm{C}$, which corresponds with emissivity in literature [16] and with our correction model (Fig. 15). Additionally, we decided to answer how emissivity changes could influence the parameter $t_{8 / 5}$. In order to do this, an investigation of emissivity was performed for various types of structural steels used for welded constructions, each having the same structure consisting of an $\alpha$-iron 
Fig. 15 Comparison of emissivity and $r_{i c}$ ratio as a function of temperature for investigated steel S700MC

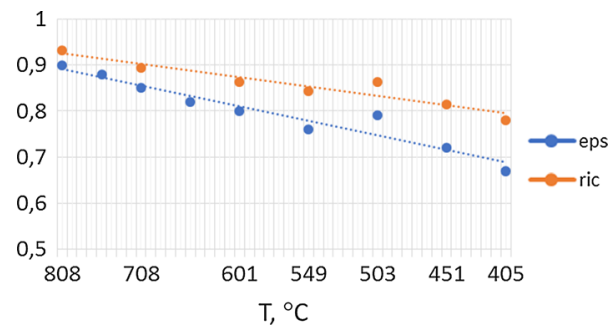

phase. The following steels were considered: S235, S355, S890, S960, S1100, and S1300. Steels S235 and S355 have ferritic-pearlite structures. In the case of S700MC steel, the structure is bainite-ferrite. Finally, steels S890, S960, S1100, and S1300 have tempered martensite structures. As the strength of steel increases, structural uniformity increases.

From all tested materials, rectangular samples were made. The surfaces of all steel specimens were intentionally grinded in order to obtain low emissivity. We wanted to simulate the most adverse surface conditions. Half of each sample area was painted with a black paint of high emissivity. Additionally, the paint was sure to withstand heating to about $900^{\circ} \mathrm{C}$. The test procedure was divided into two independent stages. The first stage was to determine the emissivity of paint at $100^{\circ} \mathrm{C}$. This test was performed with a simple resistive heater, making constant contact temperature measurements with a thermocouple. According to this test, it was found that the paint has an emissivity of $\varepsilon_{\text {paint }}=0.93$. In the second stage, all samples were heated for about $30 \mathrm{~min}$ in a soldering oven to $500^{\circ} \mathrm{C}$ and next $800^{\circ} \mathrm{C}$. Knowing the emissivity of the painted part, the emissivity of the uncovered part of the sample was calculated using a comparative method implemented in the software dedicated to the infrared camera (Fig. 16). The estimated emissivity values were presented in Table 4. It was found that for samples made of materials having similar structures, the values of emissivity are close to each other and had a relatively low level. It was especially clear for the S890, S960, S1100 steels, where the difference in emissivity was less than 0.05. Additionally, it can be seen that in general higher uniformity of structure leads to lower emissivity. At temperatures of about $800^{\circ} \mathrm{C}$ (samples taken out of oven cooled quickly), emissivity is higher and the scatter of values is less than for the temperature $500{ }^{\circ} \mathrm{C}$. To estimate changes in the parameter time $t_{8 / 5}$ caused by different surface emissivity, boundaries of possible emissivity change for $500{ }^{\circ} \mathrm{C}$ and $800^{\circ} \mathrm{C}$ were assumed, which were, respectively, (0.16-0.65) and (0.8-0.95). Using these emissivity boundaries for steel S700MC, possible changes in measured temperature by infrared camera were calculated as well as differences in estimated parameter $t_{8 / 5}$. Results are presented in Fig. 17.

In Fig. $17, \mathrm{dt}_{0}=15.7 \mathrm{~s}$ is equal to $\mathrm{t}_{8 / 5}$ for steel $\mathrm{S} 700 \mathrm{MC}$ during the thermal cycle id 7 and was estimated using a proposed correction model. The time $\mathrm{dt}_{0}$ can be treated as an reference value for relative error calculation. The time $\mathrm{dt}_{\mathrm{u}}=19.9 \mathrm{~s}$ is calculated for the upper boundary (green line) following from the emissivity change from 0.16 to 0.65 and time $\mathrm{dt}_{\mathrm{d}}=9.9 \mathrm{~s}$, which is calculated for the boundary (red line) following from the emissivity change from 0.8 to 0.95 . Percentage relative errors are, respectively, $26 \%$ 


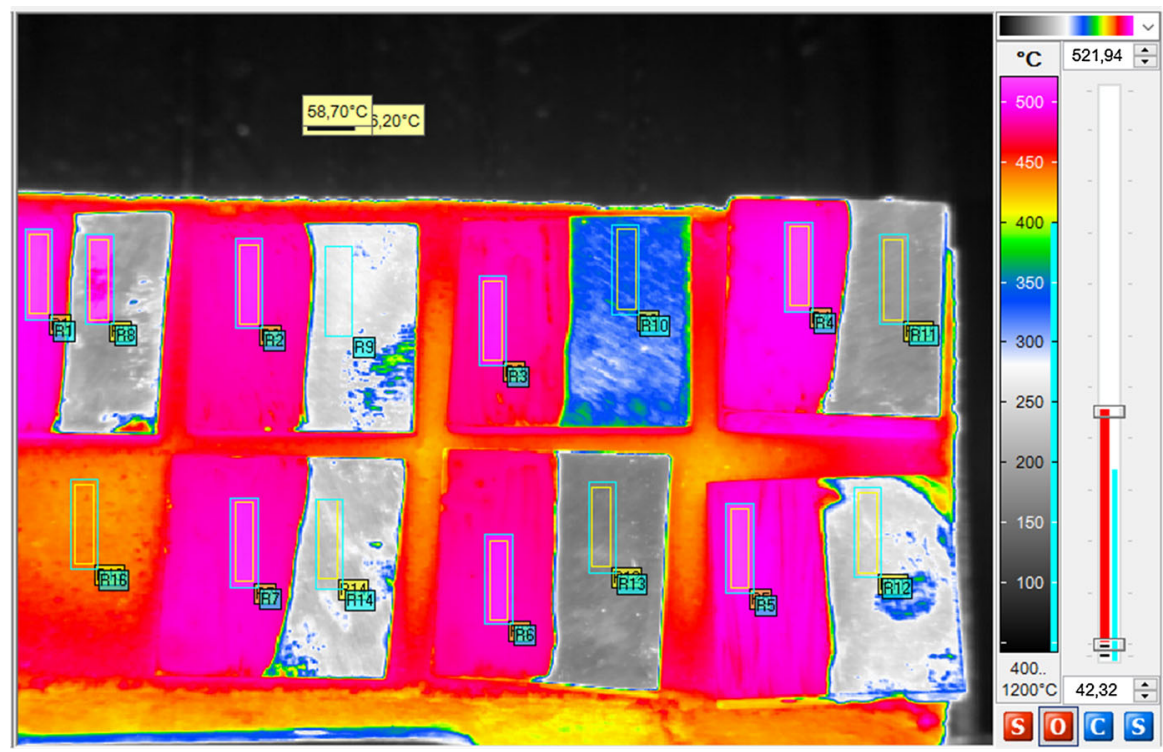

Fig. 16 Infrared image of specimens of different grades of steel during estimation of their emissivity

Table 4 Estimated emissivity of different grades of steel samples

\begin{tabular}{lll}
\hline Grade of steel & Emissivity at $500^{\circ} \mathrm{C}$ & Emissivity at $800^{\circ} \mathrm{C}$ \\
\hline S235 & 0.51 & 0.91 \\
S355 & 0.35 & 0.90 \\
S700MC & 0.28 & 0.88 \\
S890 & 0.19 & 0.86 \\
S960 & 0.16 & 0.84 \\
S1100 & 0.21 & 0.84 \\
S1300 & 0.30 & 0.84 \\
\hline
\end{tabular}

for the upper boundary and 37\% for the lower boundary. Previously calculated errors for steel S700MC (cf. Sect. 5.1.) are within the errors limit, thus application of the proposed method, even for the most unfavorable case, can reduce an error of estimation of parameter $t_{8 / 5}$. If we consider the chart presented where structural changes in the steel $\mathrm{S} 700 \mathrm{MC}$ with overlapping changes in the cooling time $\mathrm{t}_{8 / 5}$ following from emissivity fluctuation are shown, we can clearly see that underestimating the cooling time $t_{8 / 5}$ can indicate a lack of structure of ferritic structure while overestimating can indicate growth of the participation of the ferritic structure in the steel (Fig. 18).

\subsection{Investigation of HAZ Properties}

Microscopic assessment of the HAZ's microstructure of S700MC revealed that for the thermal cycle with maximum temperature in the range of $400-900{ }^{\circ} \mathrm{C}$, samples had 


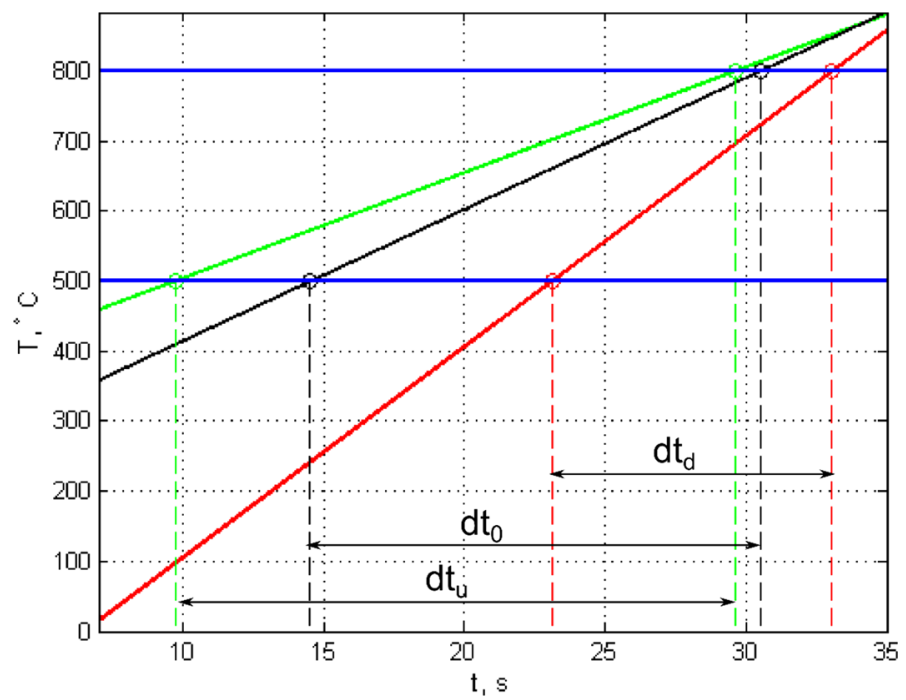

Fig. 17 Analysis of changes of parameter $t_{8 / 5}$ according to temperature change caused by emissivity change

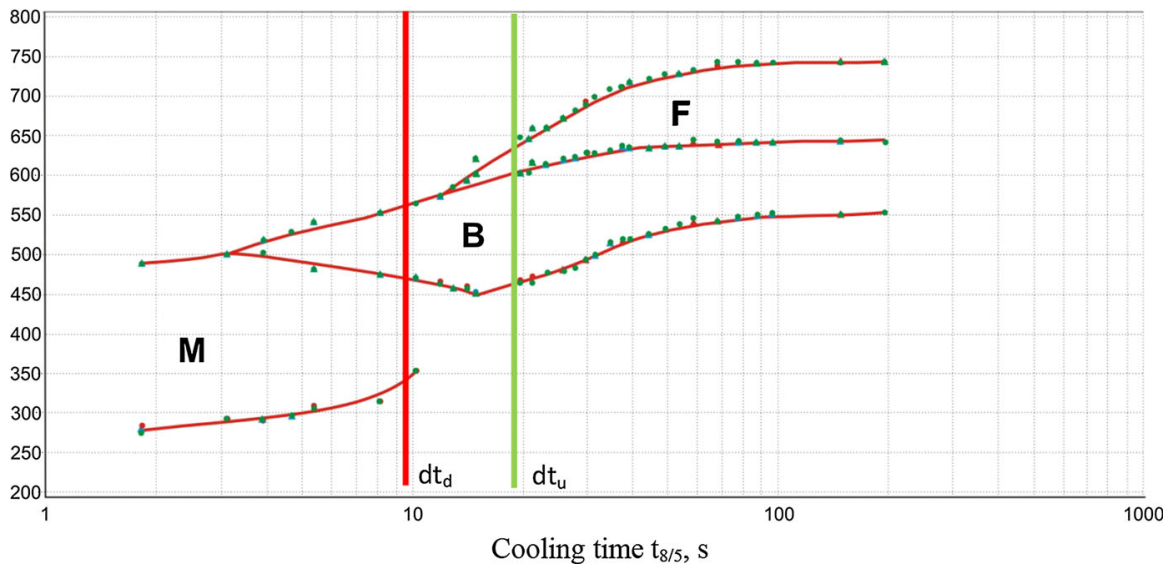

Fig. 18 Structural changes in the steel S700MC as a function of the cooling time $t_{8 / 5}$

fine-grained bainitic-ferritic structures. With an increase of maximum temperature above $900^{\circ} \mathrm{C}$, a strong growth of grain size was observed. This trend was visible up to the temperature of $1300^{\circ} \mathrm{C}$ (Fig. 19). This phenomenon has highly adverse effects on the material's properties that have been obtained through thermomechanical processing, while high temperatures decrease the influence of austenite phase grain refinement. This was mostly the case for the complex thermal cycle. Additionally, presence of large carbon nitride dispersions in all areas of the simulated HAZ was observed. This proves high thermal stability of the HAZ [13,14] (Fig. 20). 


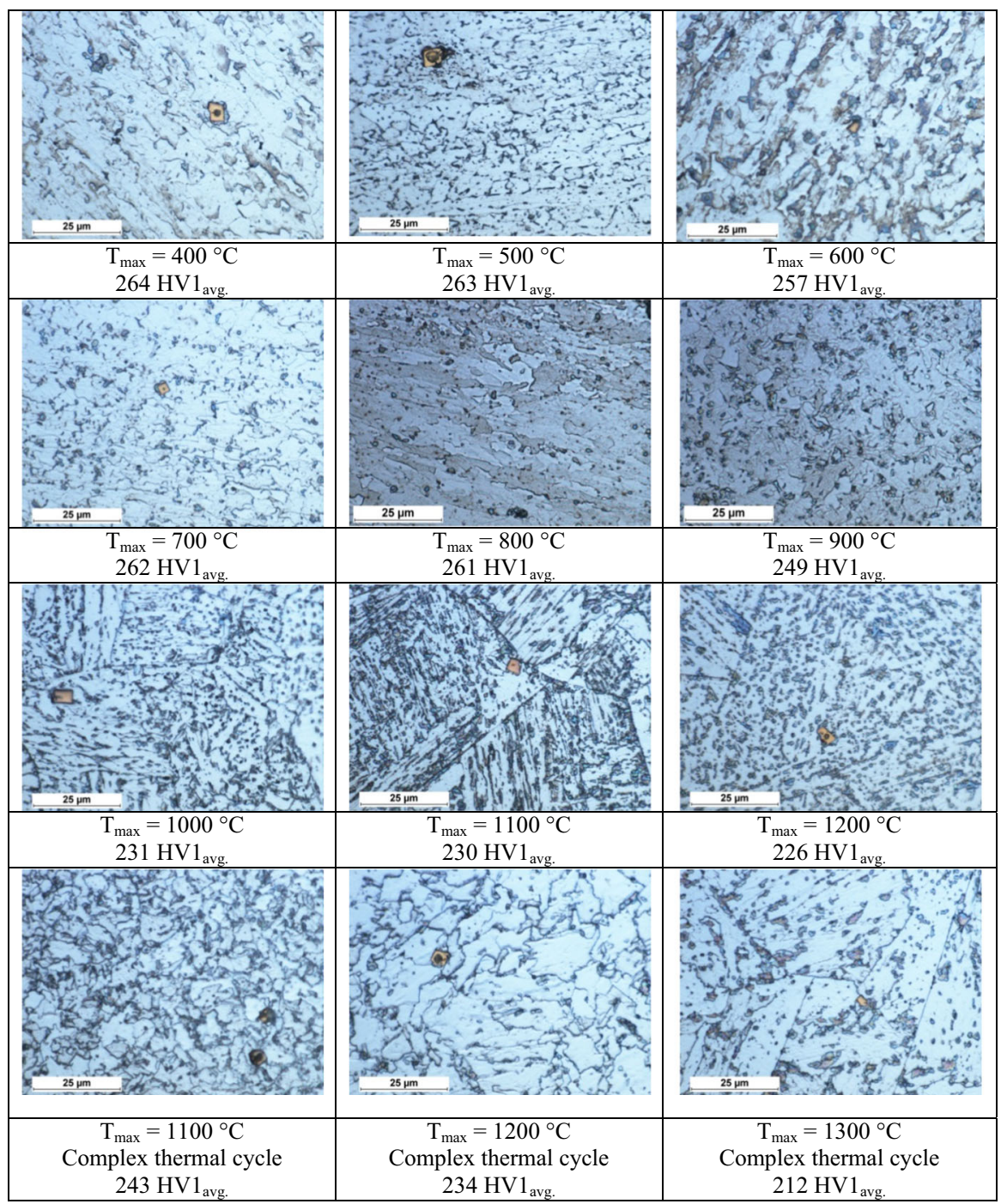

Fig. 19 The microstructure of S700MC steel HAZ as a function of max heating temperature $\left(\mathrm{T}_{\max }\right)$

The HAZ's microstructure observation results were confirmed by hardness tests made by the Vickers method. Hardness of the HAZ area, which was heated to temperatures in the range of $400-900{ }^{\circ} \mathrm{C}$, does not change significantly and is nearly on the same level as in the case of the base material. Softening of the material to about 230 HV1 (Fig. 21) was observed for samples heated to temperatures higher than $900^{\circ} \mathrm{C}$. A similar situation was also noticed for the complex thermal cycle, where increase in the maximal thermal cycle temperature caused material softening in the HAZ. With further processing of the slow cooling form temperature above $1000^{\circ} \mathrm{C}$, an increase in hardness was found. This is connected to the uncontrolled dispersion of strengthening phases. 


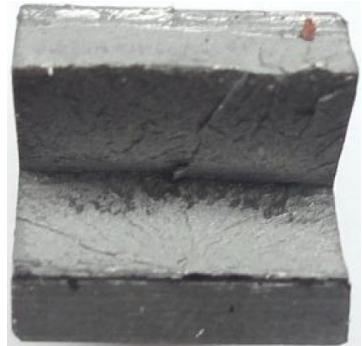

Mixed fracture

$\mathrm{T}_{\max }=500^{\circ} \mathrm{C}$

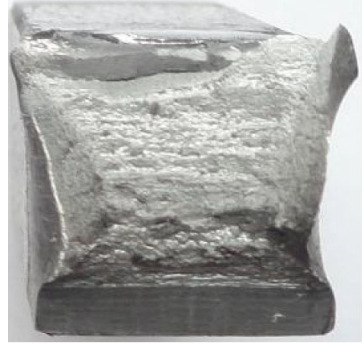

Plastic fracture

$\mathrm{T}_{\max }=900^{\circ} \mathrm{C}$

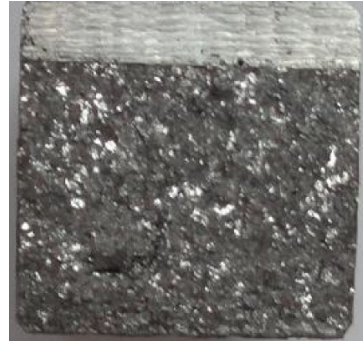

Brittle fracture

$\mathrm{T}_{\max }=1200{ }^{\circ} \mathrm{C}$

Fig. 20 View of S700MC steel $\mathrm{HAZ}$ fracture after an impact test at $-30^{\circ} \mathrm{C}$
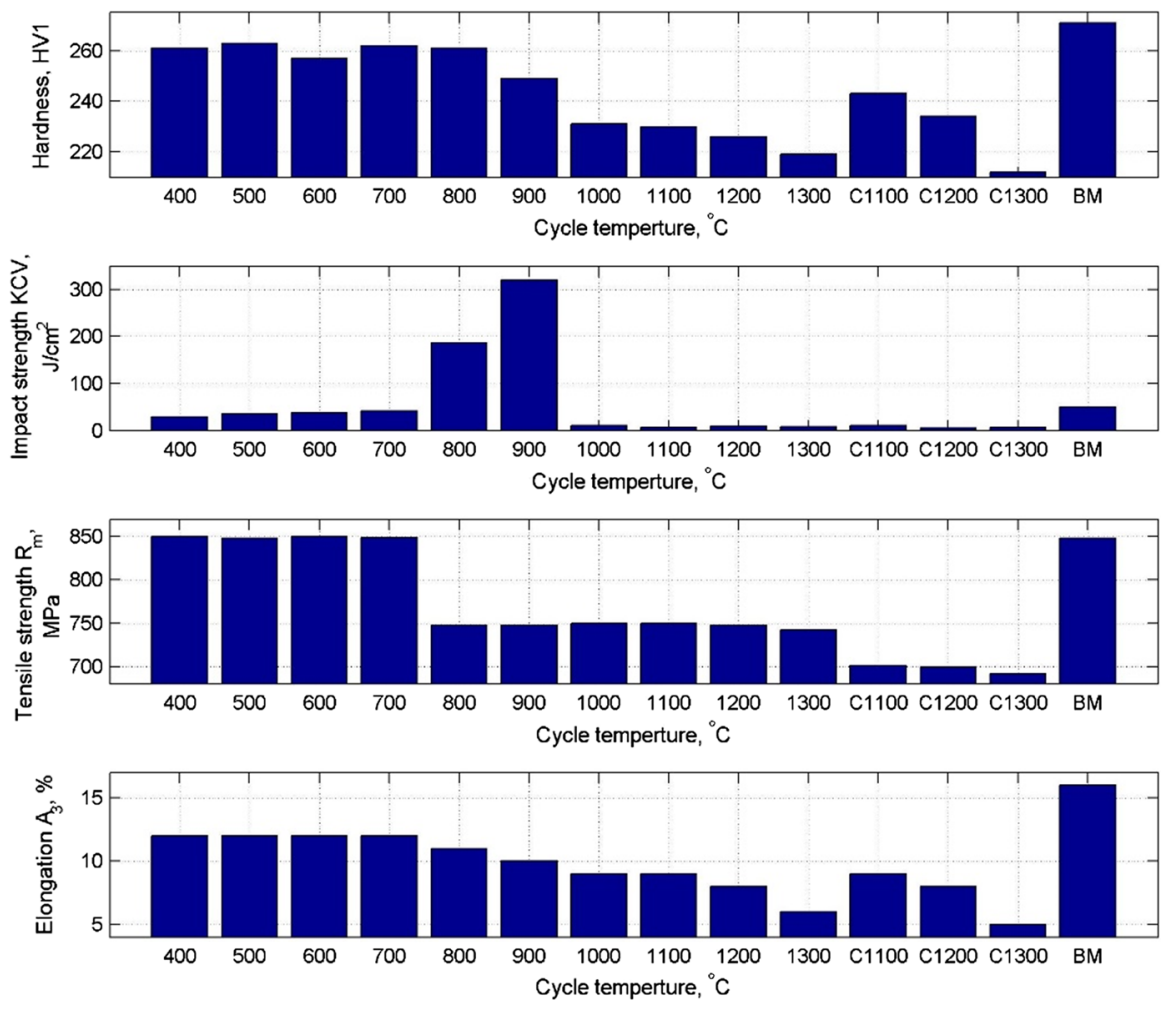

Fig. 21 Mechanical properties of S700MC steel HAZ heated to different maximum temperatures. C1100complex thermal cycle 110(500)/700(300)/500; C1200-complex thermal cycle 1200(800)/1100(500)/700; C1300-complex thermal cycle 1300(800)/1100(500)/900

It is known that welding can decrease the impact strength of a material, especially when joining is performed with high linear energy. It is thus important to measure this property. The impact strength of the $\mathrm{HAZ}$ was measured at $-30{ }^{\circ} \mathrm{C}$ using the Charpy $\mathrm{V}$ method. It was found that areas heated maximally to $700^{\circ} \mathrm{C}$ and withstanding for a long time at this temperature have significantly lower impact strength than the base 
material (decrease from $50 \mathrm{~J} \cdot \mathrm{cm}^{-2}$ to a few $\mathrm{J} \cdot \mathrm{cm}^{-2}$, Fig. 20). This was caused by the aging process and a blockade of dislocations by carbon and nitrogen. In the range of $800^{\circ} \mathrm{C}$ to $900^{\circ} \mathrm{C}$, a drop of hardness and tensile strength connected with an increase in impact strength is observed. It is caused by a disappearance of the dispersion strengthening and the process of recrystallization. When the HAZ was heated to a maximum temperature above $1000^{\circ} \mathrm{C}$, there was a rapid decrease in impact strength strongly connected to the growth of grains. This all proved that the material properties in the HAZ are strongly connected with temperature introduced into the joint during the welding process $[12,13]$.

Tensile strength tests were made on samples taken from material parts covering the HAZ and the neighboring area. Analysis of the results gathered in Fig. 15 reveals that for samples heated for a short time to a temperature maximum from $400^{\circ} \mathrm{C}$ to $700{ }^{\circ} \mathrm{C}$, there was no considerable change in tensile strength in comparison with the base material. For increased maximum temperatures in thermal cycles, a drastic drop of tensile strength in the HAZ (about $100 \mathrm{MPa}$ ) comparing to base material occurred. Also in the complex thermal cycle, higher temperature and longer cooling time led to lowering of tensile strength. Elongation of samples where the HAZ was heated to a max. $700{ }^{\circ} \mathrm{C}$ was on the $12 \%$ level, while for the base material it was $16 \%$. For higher temperatures, elongation of the material in the HAZ decreased to $6 \%$ (Fig. 15). A lack of sufficient plastic properties can lead to the appearance of brittle fractures (Fig. 16) in overheated HAZs, which is highly unwanted. The same loss of plasticity was observed for complex thermal cycles. Therefore, the welding process should be conducted in a way that allows minimization of the width of the HAZ, and therefore unwanted properties.

\section{Conclusions}

The paper presents results of research devoted to finding the method of monitoring of a weld joint during the welding process. The author's proposed application is for infrared thermography as a contactless method of measurement of HAZ temperature distribution and assessment of its properties on the basis of measured maximum temperature as well as cooling time $t_{8 / 5}$ which is connected with HAZ properties. Experiments performed during the research allowed identification of mentioned parameters and the joining of them with the results of metallographic inspections as well as mechanical tests. The obtained results from the monitoring point of view are promising. There is a relationship between maximum temperature of a thermal cycle and cooling time as well as HAZ properties. The most dangerous aspect from a practical application point of view is the area of low plasticity located in the high temperature (overheated to $1200^{\circ} \mathrm{C}$ ), coarse-grained part of the HAZ. Parts of the HAZ heated to about 800$900^{\circ} \mathrm{C}$ have the highest impact strength. Effects of dispersion strengthening vanish, and the growth of grains is limited. This leads to shortening of a distance on which unwanted effects of overheated HAZ are present. According to that, it can be stated that the best HAZ properties were obtained with a heating temperature of about $700^{\circ} \mathrm{C}$. Discovery of relations between HAZ properties and temperatures and cooling times was possible on the basis of the application of a temperature correction model to esti- 
mate the temperatures $800{ }^{\circ} \mathrm{C}$ and $500{ }^{\circ} \mathrm{C}$. This approach seems to be a good solution in laboratory conditions, however, in real life could give errors. In the article, errors of the cooling time depended on emissivity changes, which were estimated. Influence of the emissivity change could be important; thus, correction of temperatures became a very important task. The proposed model is matched to emissivity of the investigated steel S70MC, however, applied to different steels welded in different conditions could partially reduce an error of the cooling time estimation, $t_{8 / 5}$. To reduce the error of $t_{8 / 5}$, estimations were important to estimate model parameters for the exact investigated material. The authors started research on the investigation of emissivity of different grades of steel for different temperatures in order to build space for correction model parameters useful for different kinds of steels and welding conditions. Knowing that the maximum temperature could have the most influence on the HAZ's properties, the proposed method could be improved to find relative measurements of the temperatures and corresponding cooling times where the reference point can be defined by a maximum temperature acquired during the thermal cycle. Application of the proposed method in real-life serial production of welded objects can be realized even if each time designation of a maximum heating and cooling time has to be performed. Development on this approach will be the next step of the authors' further research.

Acknowledgements This work was partially funded through the following research Grant: "Control properties and structure of steel joints for thermomechanically processed high yield”, No. N N507 321040, Silesian University of Technology in Gliwice.

Open Access This article is distributed under the terms of the Creative Commons Attribution 4.0 International License (http://creativecommons.org/licenses/by/4.0/), which permits unrestricted use, distribution, and reproduction in any medium, provided you give appropriate credit to the original author(s) and the source, provide a link to the Creative Commons license, and indicate if changes were made.

\section{References}

1. S.H. Wang, C.C. Chiang, L.I. Cha, Mat. Sci. Eng. A Struct. 344, 288 (2003)

2. J. Brózda, Nowoczesne stale konstrukcyjne i ich spawalność (Wydawnictwo Instytutu Spawalnictwa, Gliwice, 2009). [in Polish]

3. Y.T. Shin, S.W. Kang, H.W. Lee, Mat. Sci. Eng. A Struct 434, 365 (2006)

4. G.R. Wang, T.W. Lau, G.G. Weatherly, T.H. North, Metall. Trans. A 20, 93 (1989)

5. J. Brózda, J. Pilarczyk, M. Zeman, Spawalnicze wykresy przemian austenitu CTPc-S, (Wydawnictwo Śląsk, Katowice, 1983) [in Polish]

6. K. Ferenc, Spawalnictwo (WNT, Warszawa, 2007). [in Polish]

7. J. Pilarczyk, Poradnik inżyniera, cz. 1. Spawalnictwo (WNT, Warszawa, 2003) [in Polish]

8. A. Najafi-Zadeh, J.J. Jonas, S. Yue, Metall. Trans. A 23, 2607 (1992)

9. M. Fidali, W. Jamrozik, Diagnostic method of welding process based on fused infrared and vision images. Infrared Phys. Technol. 61, 241 (2013)

10. W. Jamrozik, Cellular neural networks for welding arc thermograms segmentation. Infrared Phys. Technol. 66, 18 (2014)

11. B. Kosec, B. Karpe, I. Budak, M. Ličen, M. Đorđević, A. Nagode, G. Kosec, Efficiency and quality of inductive heating and quenching of planetary shafts. Metalurgija 51(1), 71-74 (2012)

12. H. Sadiq, M. Wong, J. Tashan, R. AL-Mahaidi, X. Zhao, J. Mater. Civ. Eng. 25, 167 (2013)

13. J. Górka, Microstructure and properties of the high-temperature (HAZ) of thermo-mechanically treated S700MC high-yield-strength steel Materiali in tehnologije. Mater. Technol. 50, 617 (2016)

14. J. Górka, Weldability of thermomechanically treated steels having a high yield point. Arch. Metall. 60, 469 (2015) 
15. W. Bauer, H. Oertel, M. Rink, in Proceedings of 8th International Symposium on Temperature and Thermal Measurements in Industry and Science, pp. 301-306 (2001)

16. W. Minkina, S. Dudzik, Infrared Thermography (Wiley, Errors and Uncertainties, 2009) 